\title{
Investigating the Role DNA Methylations Plays in Developing Hepatocellular Carcinoma Associated with Tyrosinemia Type 1 Using the Comet Assay
}

\author{
Johannes F. Wentzel and Pieter J. Pretorius \\ Division for Biochemistry, North-West University, \\ South Africa
}

\section{Introduction}

Although our understanding of DNA methylation mechanisms and functions has vastly improved over the past two decades, the entire spectrum of influences of this potent mechanism is not fully grasped yet. Today, a wide variety of techniques are used to examine DNA methylation patterns but most of these methods are still relatively expensive and many are platform specific (Prokhortchouk and Defossez, 2008). The need has arisen to develop an economically viable and uncomplicated technique for DNA methylation analysis. The comet assay (single cell gel electrophoresis or SCGE) is a cost-effective, sensitive and simple technique which is traditionally used for analysing and quantifying DNA damage in individual cells (Azqueta, et al., 2011, Fairbairn, et al., 1995). By modifying this assay to be methylation sensitive, global DNA methylation can be routinely measured in cell cultures while simultaneously being able to deduce the integrity of the genetic material of the examined cells. The methylation sensitive comet assay was used to examine the effect of the accumulating metabolite, succinylacetone (SA), in hereditary Tyrosinemia type I (HT1), since hepatocellular carcinoma (HCC) frequently develops into this disease.

\section{The role of DNA methylation in maintaining genome stability}

DNA undergoes several modifications following each replication cycle of which DNA methylation is one. DNA methylation, as part of the epigenetic code, involves the addition of a methyl group to cytosine without altering the original DNA sequence. DNA methylation may take place on the number five carbon of the cytosine pyrimidine ring and this modification has been observed in every vertebrate examined (Herman, 2001, Waggoner, 2007). DNA methylation alters the biophysical characteristics of DNA which may either inhibit the recognition of certain DNA sequences by functional proteins or enable the binding of others (Prokhortchouk and Defossez, 2008).

DNA methylation is carried out by a group of enzymes called DNA methyltransferases (DNMTs) (Pogribny, et al., 2004). These enzymes not only determine the DNA methylation patterns during early development, but are also responsible for copying these patterns to the 
new strands formed during DNA replication. Based on their preferred DNA substrates, these enzymes can be divided into two different classes - maintenance enzymes (DNMT1) and de novo or pioneering enzymes (DNMT3A + B) (Sweatt, 2009).

The maintenance methyltransferase DNMT1 is responsible for copying existing methylation patterns to newly replicated, hemimethylated DNA (Kanai, et al., 2003, Sweatt, 2009). DNMT1 is also associated with other epigenetic processes such as silencing gene transcription and is known to interact with histone deacetylase 1 and 2 (HDAC1/2) (Kanai, et al., 2003). While some studies have indicated that DNMT1 has some de novo methylation activity in vitro, there is no substantial evidence indicating that this is the case in vivo (Okano, et al., 1999). Due to the relation of DNMT1 with HDAC1 and 2, it directly affects gene transcription and chromatin structure. Although the identification of hemimethylated sequences by DNMTs are still a point of discussion and uncertainty, there is some evidence suggesting that DNMT1 may be recruited by UHRF1 which can bind to partially methylated DNA (Prokhortchouk and Defossez, 2008). In short, DNMT1 is the key maintenance DNA methyltransferases which is responsible for copying the previously established methylation blueprint after every replication cycle.

The de novo methyltransferase DNMT3 typically establishes new DNA methylation patterns in specific regions, mainly in satellite repeats and retrotransposon (transposons via RNA intermediates) sequences (Gopalakrishnan, et al., 2008). The dnmt3 gene family consists of $d n m t 3 a$ and $d n m t 3 b$ which seems to have related functions (Okano et al, 1999). Studies done on rodent embryos lacking the $d n m t 3 a$ showed that these embryos developed normally but died a few weeks after birth (Bird, 2002, Mohn and Schubeler, 2009). On the other hand, mice lacking dnmt3b suffered from multiple developmental defects and were aborted (Gopalakrishnan, et al., 2008, Mohn and Schubeler, 2009). This is not only a clear indication of the importance of DNMT3 in de novo methylation but also illustrates the fundamental role of DNA methylation in early development. To summarize, DNMT3A and B are responsible for methylating previously unmethylated DNA and seem to play an imperative role in development and growth.

A fourth DNA methyltransferase, DNMT2, exists and is structurally similar to prokaryotic and eukaryotic methyltransferases. However, it shows weak or no DNA methyltransferase activity in vitro and targeted deletion of the DNMT2 gene in embryonic stem cells causes no detectable effect on global DNA methylation, suggesting that this enzyme has little involvement in establishing DNA methylation patterns (Okano et al, 1999; Klose, 2006). The methyltransferase DNMT3L is thought to be a co-factor for DNMT3a and DNMT3b and modulates their catalytic activity (Klose and Bird, 2006, Prokhortchouk and Defossez, 2008). S-adenosylmethionine (SAM) acts as a methyl donor and donates a methyl group to unmethylated cytosines within CpG islands of genomic DNA. The methyl group is transferred from SAM to the $5^{\prime}$ position from cytosine through the actions of DNMTs.

To summarize, DNMTs are at the core of the DNA methylation machinery and is not only responsible for establishing new methylation patterns in DNA but also to maintain these patterns after replication. It may even be an inseparable part of transcription. Elucidating the full extent of influence of the DNMTs will undoubtedly better our understanding of DNA methylation and will be indispensable for future medical endeavours to ultimately prevent disease. 
Maintaining global genome stability is crucial for the development and normal functioning of any organism. In eukaryotic organisms, DNA methylation is crucial for maintaining genome stability, as well as playing an important role in routine gene expression (Bird, 2002, Nag and Smerdon, 2009). Apart from ensuring a stable genome in adults, DNA methylation also plays a central role in the ordered differentiation of mammalian cells during embryonic development by activating specific genes and silencing others (Mohn and Schubeler, 2009).

Two common patterns of cytosine methylation at CpG dinucleotides have been described in the eukaryotic genome - genome-wide $\mathrm{CpG}$ methylation density, and non-random regional CpG methylation (Cottrell, 2004, Ohgane, et al., 2008). DNA methylation in adult somatic tissues typically occurs in regions called $\mathrm{CpG}$ islands while non-CpG methylation (methylation outside of $\mathrm{CpG}$ islands) is most prevalent in embryonic stem cells (Haines, et al., 2001). CpG islands are characterized by high CpG density and tend to be unmethylated under normal conditions (Duffy, et al., 2009).

As part of the epigenetic code, DNA methylation ensures diverse cellular differentiation despite a primarily static genome. There exists a complex collaboration between epigenetic mechanisms (including DNA methylation, histone modification and micro RNA systems) to orchestrate a sophisticated and cell specific gene regulation (Guil and Esteller, 2009). These epigenetic processes connect the largely static genome and transcriptome by introducing complex and dynamic networking layers of gene control (Ohgane, et al., 2008). Due to this intensive involvement of DNA methylation in the epigenome, it comes as no surprise that the abnormal regulation of these mechanisms may cause altered gene expression and ultimately disease.

\section{Abnormal DNA methylation patterns associated with cancer}

Taken into account the crucial role epigenetics play in many cellular processes, it is logical that abnormal regulation of these mechanisms may lead to misinterpreted gene expression and eventually disease. This relationship between disease and the epigenome prompted scientists to perform comprehensive research into the role epigenetics play in the aetiology of these diseases. Today there is mounting evidence of irregular epigenetic regulation in many diseases (Gopalakrishnan, et al., 2008).

In the late 1980s abnormal DNA methylation patterns were observed in all cancer types investigated. There is ample evidence indicating that disruption of epigenetically regulated expression of genes play a direct, and maybe even a causative, role in the development and manifestation of many diseases including cancer (Hirst and Marra, 2009, Sawan, et al., 2008).

In cancer cells, methylated CpGs loose their DNA methylation status and unmethylated promoter regions may become densely methylated. This puzzling phenomenon prompted scientists to believe that both the loss and/or gain of DNA methylation are linked to cancer (Ehrlich, 2002, Gopalakrishnan, et al., 2008, Hirst and Marra, 2009). DNA methylation, as part of the epigenome, is critical in expanding and regulating the expression of the genome which in its turn determines the phenotype. The epigenome is subsequently influenced by internal cues as well as a large range of environmental factors (Lambert and Herceg, 2008). If these processes are not tightly regulated it can lead to changes in DNA methylation and histone modification patterns resulting in the disruption of important cellular processes 
including gene expression, DNA repair and tumour suppression - which may lead to cancer development. For instance, mutations in genes encoding for DNA methyltransferases lead to changes in their expression and to altered DNA methylation patterns (Brenner, et al., 2005). CpG islands are usually located in non-tissue specific promoter regions of genes and are normally unmethylated. Tumour cells exhibit global hypomethylation of the genome accompanied by region-specific hypermethylation (Szyf, 2006) (see figure 1).

A. Gene of a normal cell

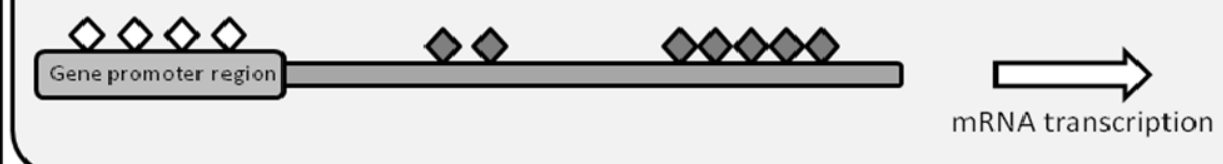

B. Gene of a cancer cell

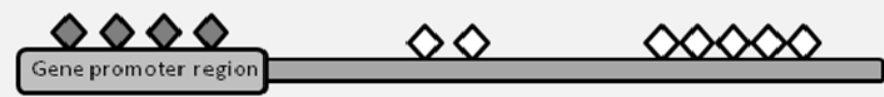

Hypermethylation

Hypomethylation

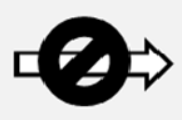

No mRNA transcription

Unmethylated $\mathrm{CpG}$ cites

Methylated CpG cites

Fig. 1. Different methylation patterns in normal (A) and malignant (B) cells. Cancer cells exhibit global hypomethylation of the genome accompanied by region-specific hypermethylation.

DNA hypomethylation can be described as the demethylation of the typically methylated regions of genes. The three main mechanisms proposed to contribute to cancer development due to hypomethylation is: (1) an increase in genomic instability, (2) reactivation of transposable elements and (3) loss of imprinting (Hirst and Marra, 2009). This may lead to the weakening, or even lifting, of the transcriptional repression in silenced gene promoters which in turn may contribute to the unwanted or abnormal expression of genes (Wilson, et al., 2007). This demethylation pattern can be seen in several cancers including metastatic hepatocellular cancer, cervical cancer, prostate tumours, and brain cancers (Das and Singal, 2004). This abnormal demethylation can also cause chromosomal rearrangement and translocations which might negatively influence genome stability (Ehrlich, 2002).

Hypermethylation of DNA is far more common in tumour cells than hypomethylation and mainly occurs in the promoter regions of genes leading to their transcriptional silencing (Moss and Wallrath, 2007). This is apparent from the inactivation of the tumour suppressor genes, adhesion molecules and repair enzymes which contribute to cancer development (Gopalakrishnan, et al., 2008). It has been confirmed that one or more genes are 
hypermethylated in tumours. Examples of such studies are those concerning lung cancer (where over 40 genes were found to have altered methylation patterns) and leukaemia where many genes exhibit hypermethylation (Tsou, et al., 2002). CpG island hypermethylation also seems to increase in metastasis suppressor genes while increasing histone alterations (Lujambio and Esteller, 2007).

Over the past decade studies have shown that epigenetic alterations are present in many malignancies and in contrast to genetic alterations, epigenetic changes are theoretically reversible - making them opportune targets for the development of therapeutic and preventive drugs. Better insight into the mechanisms involved in DNA methylation-related diseases are of cardinal importance for the development of more effective treatments.

From this description of the crucial role DNA methylation plays in maintaining the integrity of the vertebrate genome, accurate measurement of the basic level of DNA methylation and deviations thereof become of paramount importance. Methods used to measure DNA methylation range from array technology to describe the methylome to evaluating the promoter assosiaded $\mathrm{CpG}$ islands of individual genes. The majority of the methods where global DNA methylation is investigated give a combined measure of DNA methylation of all the cells involved. The comet assay can be modified to measure DNA methylation of single cells. The advantages of this approach is that, because of the versatility of the comet assay, a spectrum of additional information pertaining to the integrity of the genome can be collected in one experiment e.g. DNA damage and repair.

\section{Using the methylation sensitive comet assay to investigate the role DNA methylation plays in hepatocellular carcinoma associated with tyrosinemia type 1}

\subsection{Comet assay}

Presently, a wide variety of techniques are used to examine DNA methylation patterns, but most of these methods are relatively expensive and many are platform specific (Prokhortchouk and Defossez, 2008). The need has arisen to develop alternative and more economically viable techniques for DNA methylation analysis.

The comet assay (or single cell gel electrophoresis assay) is a cost-effective, sensitive and simple technique, which is traditionally used for analysing and quantifying DNA damage in individual cells (Azqueta, et al., 2011, Fairbairn, et al., 1995). In 1984 Östling and Johanson developed the alkaline single cell gel electrophoresis assay as a novel approach for detecting DNA lesions. Today this method is regularly used in biomonitoring and mechanistic studies in a large range of in vitro and in vivo systems (Lovell and Omori, 2008). In this method, specific cells are harvested and encapsulated in a low melting point agarose gel. This gel solution is then applied to a glass slide covered in high melting point agarose.

The agarose gel acts to keep the cells separate from each other and to serve as staging point for all the treatments that follow. Encapsulation is followed by chemical (usually a high salt concentration solution) lysis. The supercoiled DNA attached to the nuclear matrix unwinds due to the high $\mathrm{pH}(\sim 12.3)$ of the alkaline lysing solution. The encapsulated nucleoids are now exposed to an electric current causing the damaged fragments of the DNA to migrate towards the anode - forming the so called tail of the comet. After electrophoresis, Tris- $\mathrm{HCl}$ is 
used to neutralize the alkaline electrophoresis buffer followed by staining with ethidium bromide. Imaging software is then used to measure the fluorescence and to determine the extent of DNA damage (Collins, et al., 1997, Rojas, et al., 1999). The genomic integrity of the individual cell is then calculated by the tail migration by either measuring the tail length, tail moment or percentage DNA in the tail in (see figure 2 for an example of a comet) (Lovell and Omori, 2008).

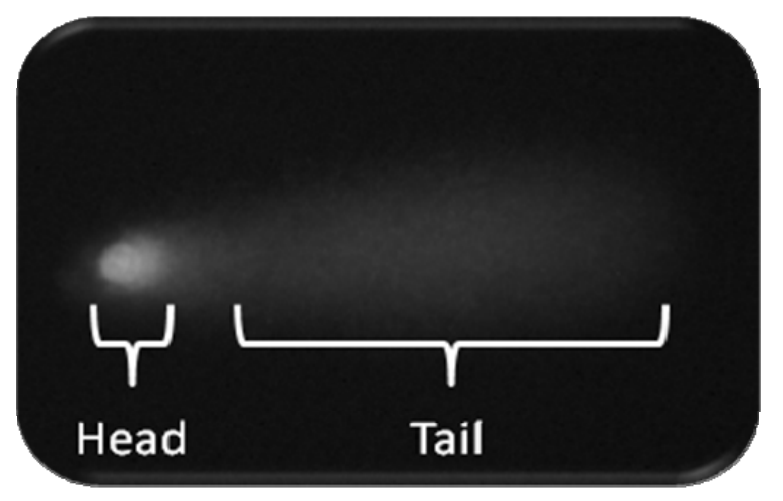

Fig. 2. The DNA fragments migrate from the nucleoid forming a comet like appearance. The general shape of a comet clearly indicating its head (nucleoid) and tail (migrated DNA) after electrophoresis and staining.

The comet assay is widely used for genotoxicity studies and determining DNA repair capacity and a variety of DNA lesions can be detected using the alkaline version of the single cell gel electrophoresis (comet) assay, including DNA double (DSB) and single strand breaks (SSB), as well as alkali-labile sites (ALS) (Collins and Gaivao, 2007).The flexibility of the comet assay is further expanded with the use of specific restriction endonucleases. Modifications to the comet assay have allowed the use of lesion specific restriction enzymes to detect specific base modifications as DNA single strand breaks (Collins and Gaivao, 2007, Epe, et al., 1993). For example, Fpg acts both as an AP-lyase and a $N$-glycosylase, allowing it to release modified purines from double stranded DNA (Tice, et al., 2000). It was also shown that Fpg strongly enhances the detection of mitomycin C (MMC) and ethylmethanesulphonate (EMS) induced DNA modifications (Andersson and B.E.Hellman, 2005). Damaged pyrimidines are removed in a similar manner from double stranded DNA by the endonuclease Endo $l l l$ (Speit, et al., 2009).

By using methylation sensitive restriction endonucleases, the traditional alkaline comet assay can be modified to be methylation sensitive. This method enables the routine measurement of global, as well as CpG island DNA methylation in a variety of cells while simultaneously determining the genetic integrity of examined cells.

\subsection{Modification of the comet assay to be methylation sensitive}

The methylation sensitive comet assay employs the isoschizomeric restriction enzymes HpaII and MspI. These enzymes recognize the same tetranucleotide sequence (5'-C C G G- 
$\left.3^{\prime}\right)$ but display differential sensitivity to DNA methylation. HpaII is inactive when any of the two cytosines is methylated, but it digests the hemimethylated 5'-CCGG-3' at a lower rate compared with the unmethylated sequences. On the other hand, MspI digests 5'-CmCGG-3' but not 5'-mCCGG-3'. These restriction enzymes features have been used to assess the global DNA methylation status of DNA preparations in radio labeling experiments (Fujiwara and Ito, 2002, Pogribny, et al., 2004). Difference in methylation sensitivity of the isoschizomeric restriction endonucleases Hpall and $M s p l$ was also used to demonstrate the feasibility of the comet assay to measure global DNA methylation level in individual cells. Thus, when applied to the comet assay, one would expect that a higher level of DNA methylation of the $\mathrm{CpG}$ sequence in this site would result in a larger difference in the global amount of DNA in the comet tails of HpaII digested versus Msp I digested DNA.

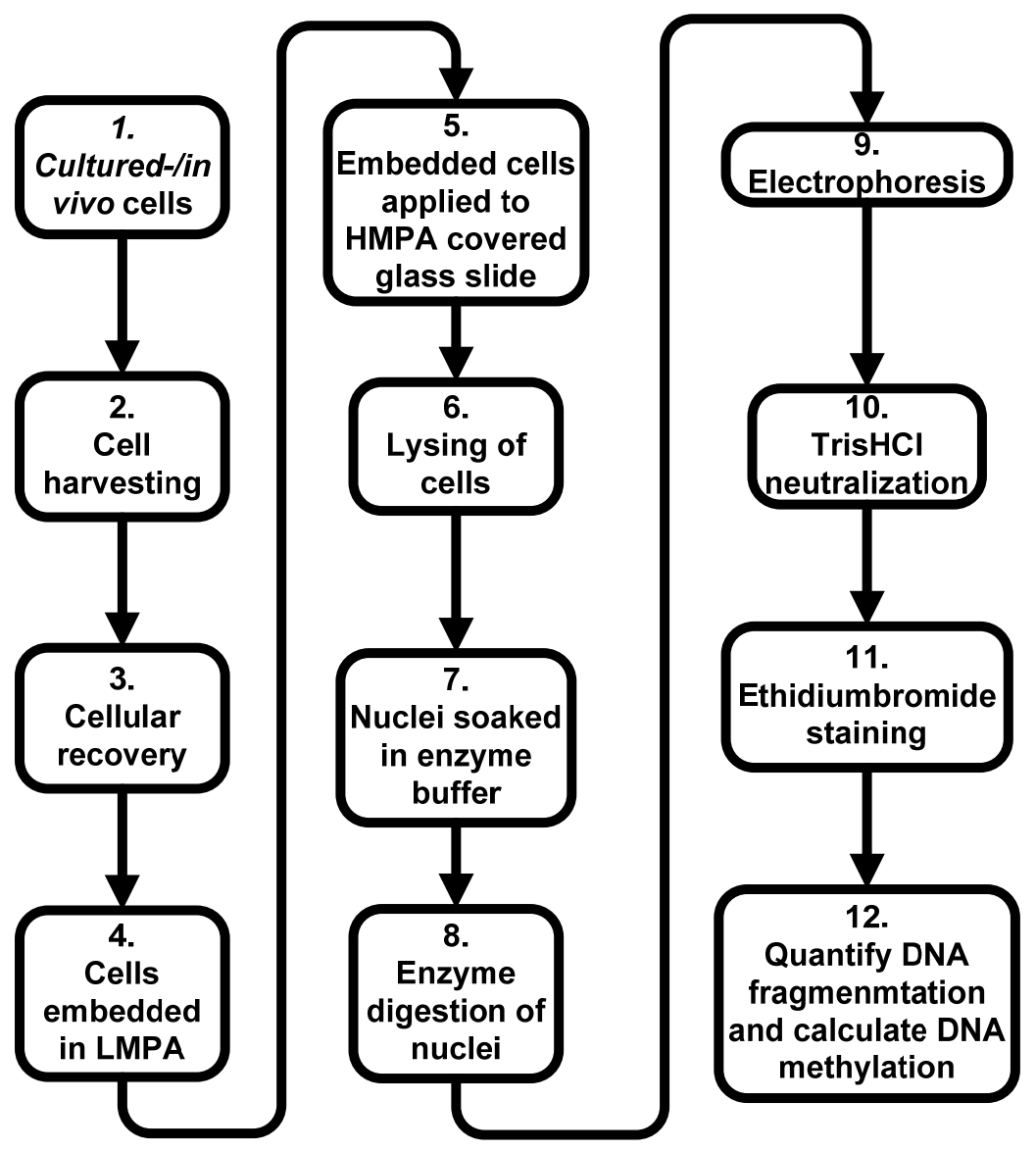

Fig. 3. A summary of the methylation sensitive comet assay method 


\subsubsection{Cell harvesting and repair}

One of the advantages of the comet assay is the possibility to employ a wide variety of cells, ranging from cultured cells to cells harvested in vivo. Different cell lines require specific cellular harvesting techniques, for instance, cultured HepG2 is an adherent cell line and must be separated from their growth chambers, adjacent cells and other material in suspension, while leucocytes have to be separated from other cells and substances present in blood. Many of the cultured cell lines require a proteinase harvesting step to detach them from the growth chamber and adjacent cells (see section 4.2.4). During this harvesting process, cells are exposed to trypsin which negatively influences the cell's cellular integrity that may lead to DNA fragmentation. This makes a repair phase essential before the cells can be used in the comet assay. For recovery, cells were incubated in an orbital shaker (to prevent cells from adhering to the container) in DMEM nutrient medium for 2 hours at $37^{\circ} \mathrm{C}$ directly after trypsin harvesting. In order to undergo electrophoresis to quantify the extent of DNA damage and/or fragmentation, cells must first be encapsulated in agarose gel.

\subsubsection{Cell encapsulation and lysis}

After the recovery phase, cells are encapsulated in a low melting point agarose gel and applied to a glass slide covered with a thin layer of high melting point agarose. In order for the comet assay to illustrate the integrity of a cell's genetic material, the nucleoides must first be exposed. The encapsulated cells are submerged in lysis solution consisting of sodium chloride $(\mathrm{NaCl})$ [2.5 - 5M], ethylenediaminetetraacetic acid (EDTA), 10\% dimethyl sulfoxide (DMSO) and $1 \%$ Triton $\mathrm{X}-100$ at $4^{\circ} \mathrm{C}$. This solution is formulated to disrupt cellular material in the shortest amount of time, while leaving the nucleus unharmed. The high $\mathrm{NaCl}$ concentration draws water out of the cells by osmotic action. The exact $\mathrm{NaCl}$ concentration should be determined empirically for the specific type of cells used to prevent it from negatively influencing the cell's genomic integrity. EDTA is commonly used to forage metal ions in order to deactivate metal dependant enzymes that may cause DNA damage. DMSO is an excellent polar aprotic solvent and is especially effective solvent in reactions involving salts. It acts as a hydroxyl radical scavenger formed when iron is released from blood while also acting to inhibit the formation of secondary DNA structures (Chakrabarti and Schutt, 2001). Studies concluded that an $8-15 \%$ dilution of DMSO yields the best lysis results (Wentzel, unpublished M.Sc results). Finally, the non-ionic detergent Triton X-100 is used to solubilise cell proteins and membranes.

\subsubsection{Treatment of exposed nucleoids with restriction enzymes Hpall and Mspl}

Nucleoids are treated with restriction enzymes HpaII and MspI just after the cell lysis step. In order to create favourable restriction conditions, the slides containing the nucleoids are soaked in enzyme reaction buffer for at least 10 minutes. The enzyme reaction buffer consist of $5 \times 10^{-3} \mathrm{~mol} / 1 \mathrm{TrisHCl}, 5 \times 10^{-3} \mathrm{~mol} / 1 \mathrm{NaCl}, 5 \times 10^{-4} \mathrm{~mol} / 1$ merkapto-ethanol and $1 \times 10^{-3} \mathrm{~mol} / 1$ EDTA which is a close recreation of the Tango buffer usually used with these enzymes. Experiments have indicated that this composition of the reaction buffer is absolutely crucial for normal enzyme function and care should be taken in its accurate preparation. After the slides have been soaked in reaction buffer (and the excess liquid removed to prevent any negative affect it may have on the enzyme reaction) the enzyme mixture is directly applied 
to the slides. Each enzyme mixture is composed of 1.5 unit of MspI or HpaII, $10 \mu \mathrm{l}$ of Tango buffer (Fermentas) and filled to $100 \mu \mathrm{l}$ with molecular grade $\mathrm{H}_{2} \mathrm{O} .100 \mu \mathrm{l}$ of this enzyme mix is then carefully applied to each slide and covered with a cover slip. The slides are then placed in a damp plastic container lined with towel paper that was preheated to $37^{\circ} \mathrm{C}$. After 5 minutes of incubation the slides are covered with towel paper soaked in reaction buffer to keep the slides from drying out while incubating for another 55 minutes. In some cases, experimental results showed little or no DNA digestion. This may be the result of tightly packed nuclei where the majority of the enzymes recognition sites are unavailable, thus leading to poor DNA digestion. This can be overcome by treating the cells directly with a $5 \%$ proteinase $\mathrm{K}$ solution just after lysis.
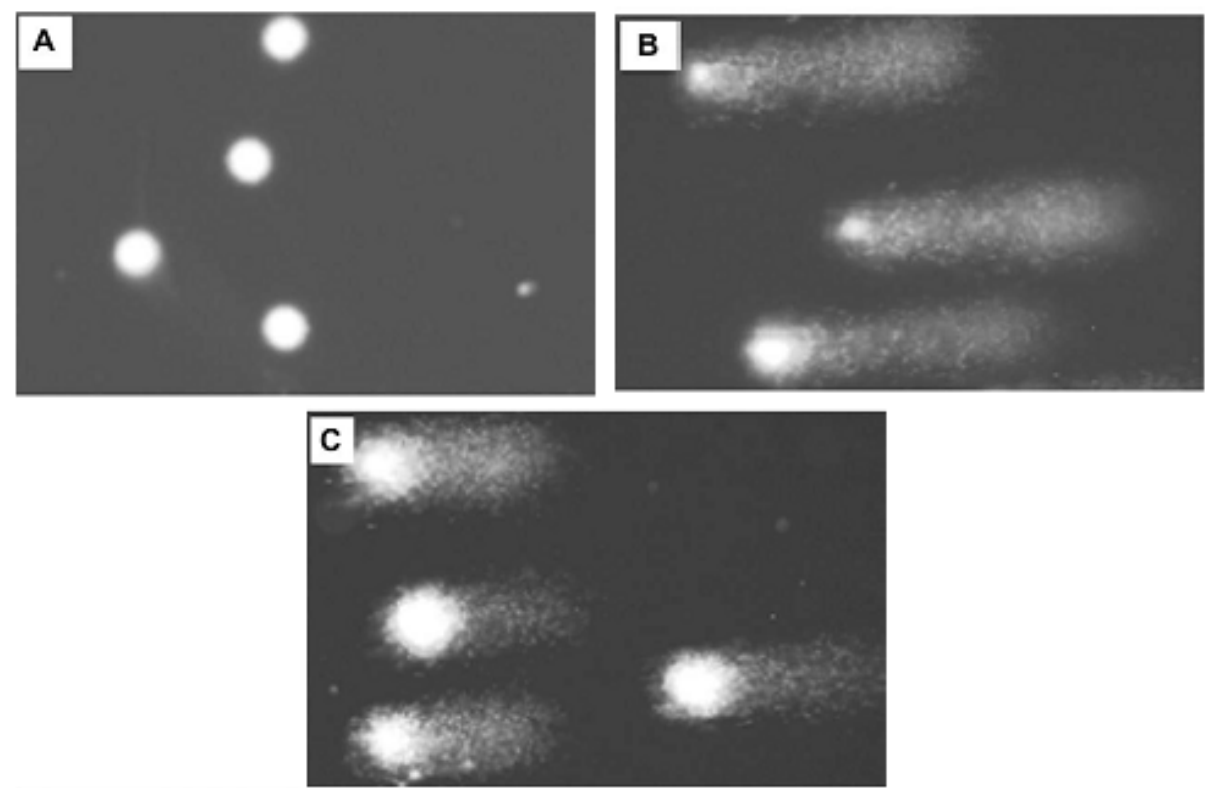

Fig. 4. Comets created by the treating nucleoids with the isoschizomeric enzymes MspI and HpaII: Nucleoids without enzyme treatment (A), with MspI treatment (B), and with HpaII treatment $(\mathrm{C})$.

\subsubsection{Proteinase $\mathrm{K}$ treatment of cells}

Nucleoids prepared from cells in the later phases of the growth curve (or even cells with a high passage number) tend to be tightly packed, making enzyme digestion only partially effective. As a last resort, this problem can be overcome by soaking the slides in electrophoresis buffer for 30 minutes just before enzyme treatment. This alkaline solution assists with unwinding the nucleus but can cause DNA damage leading to unwanted fragmentation. An alternative is to treat the cells with proteinase K (Qiagen) (1.0 -1.5 mM) solution which is a subtilisin-type protease. This broad spectrum serine protease is commonly used to inactivate nucleases when isolating or purifying DNA (QIAGEN, 2005). Proteinase $\mathrm{K}$ acts on the nucleosomes causing the DNA to relax and unwind, making 
restriction enzyme recognition sites more accessible for MspI and HpaII (DNA-protein interactions that have survived the lysis step, are destroyed with this enzyme treatment). After proteinase $\mathrm{K}$ treatment there is a visible increase in the average tail percentage between the different enzyme digestions indicating the effectiveness of proteinase $\mathrm{K}$ in relaxing the nucleoids of HepG2tTS cells (see figure 5). Although the increase in DNA methylation was small, we observed these differences in several experiments And can also safely say that there was no DNase activity in the Proteinase K preparations The tail-DNA increase observed after restriction enzyme digestion in the Proteinase $\mathrm{K}$ treated cells can thus be ascribed to an increase in the number of available restriction sites due to differences in DNA methylation sensitivity.

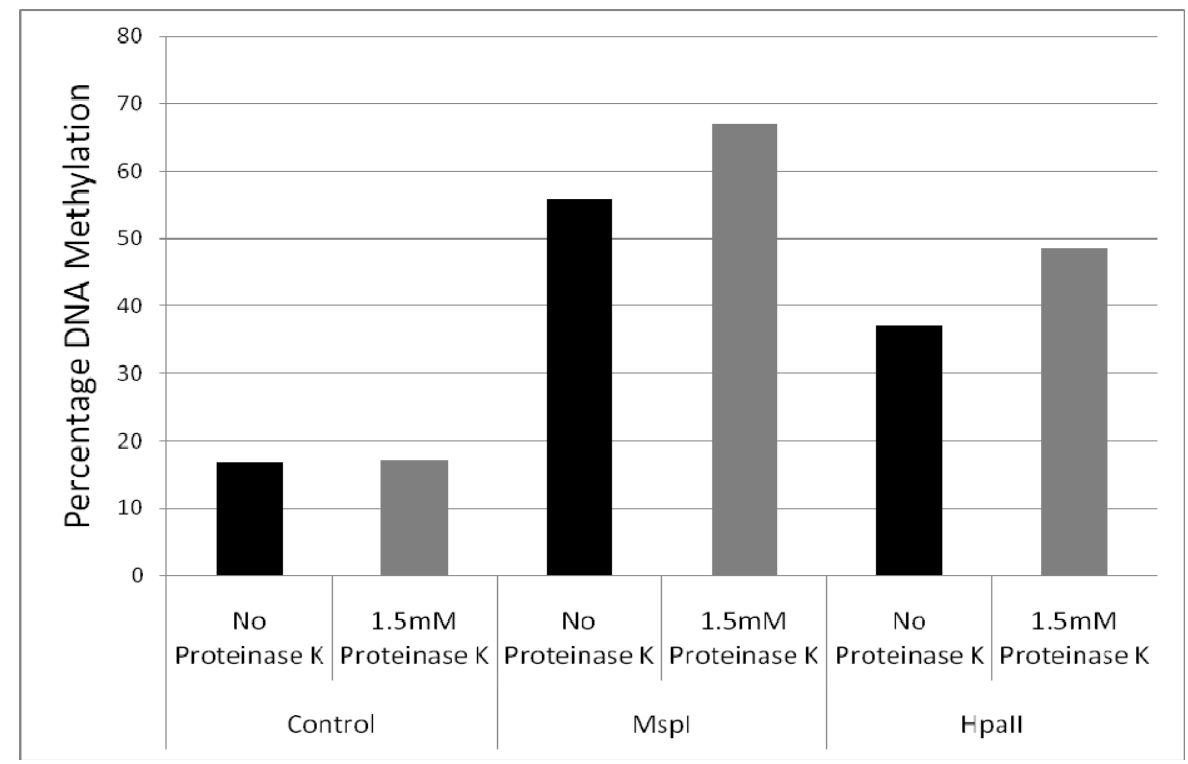

Fig. 5. Proteinase K treatment of the nucleoids. The nucleoids were treated with Proteinase $\mathrm{K}$ before treatment with restriction enzymes.

\subsubsection{Investigation of DNA methylation within CpG islands using the methylation- sensitive endonuclease Notl}

In adult somatic tissues DNA methylation typically occurs in regions called CpG islands. CpG islands are characterized by high CpG density and tend to be unmethylated under normal conditions (Duffy, et al., 2009). According to Gardiner-Garden sequence criteria, a $\mathrm{CpG}$ island is defined as a region greater than 200 bp with a $\mathrm{G}+\mathrm{C}$ content greater than $50 \%$ (Gardiner-Garden and Frommer, 1987). Interestingly, over $40 \%$ of human genes contain $\mathrm{CpG}$ islands in their promoter regions and it is strongly believed that transcription activation and silencing of these genes are directly influenced by DNA methylation (Illingworth and Bird, 2009). To examine methylation in CpG islands, the methylationsensitive enzyme NotI can be used, since it has a 5'-GC^GGCCGC-3' recognition site and acts mainly on target sites within CpG islands (Fazzari and Greally, 2004). Therefore, the 
slides were soaked in restriction enzyme reaction buffer $(50 \mathrm{mM}$ Tris- $\mathrm{HCl}, 10 \mathrm{mM} \mathrm{MgCl}$, $100 \mathrm{mM} \mathrm{NaCl}$, and $0.1 \mathrm{mg} / \mathrm{ml}$ bovine serum albumin [BSA]) for $10 \mathrm{~min}$. An enzyme mixture consisting of NotI $(1.5 \mathrm{U} / 100 \mu \mathrm{l})$ in $1 \times$ Buffer O (Fermentas) was prepared, and $100 \mu \mathrm{l}$ of this enzyme mixture was applied to the slides and covered with a coverslip. The comet assay was then performed as described above.

\subsubsection{Electrophoresis, staining and quantification of nucleoids}

After incubation, the slides are placed in an electrophoresis tank and covered with electrophoresis buffer (usually around $5 \mathrm{~mol} / 1$ sodium hydroxide $(\mathrm{NaOH})$ and $0.4 \mathrm{~mol} / \mathrm{l}$ EDTA, pH 13). Electrophoresis is performed at a potential difference of $30 \mathrm{~V}$ and a current of $300 \mathrm{~mA}$ for 45 minutes while the buffer is maintained at $4^{\circ} \mathrm{C}$. Experiments showed that electrophoresis at $4^{\circ} \mathrm{C}$ is extremely crucial for optimum DNA fragment migration. After electrophoresis the slides are placed in a Tris- $\mathrm{HCl}$ neutralisation buffer for approximately 15 minutes. This buffer acts to neutralize the alkaline electrophoresis and prevents it from causing unwanted DNA damage $\backslash$ fragmentation. The slides are then stained with $10 \mu \mathrm{g} / \mathrm{ml}$ ethidiumbromide for at least an hour at $4^{\circ} \mathrm{C}$ and rinsed afterwards with distilled water.

Finally, the comet images are captured with a fluorescence microscope (x200 magnification) and scored using computer software (Comet IV from Perceptive Instruments Ltd). Due to intercellular variation, it is highly recommended that at least 200 comets are scored at random and that all experiments be done in duplicate. The data generated can then be analyzed and the results are expressed as percentage CpG methylation. This is calculated using the ratio between the average percentage tail DNA of HpaII- and MspI-digested DNA, that is, 100 - HpaII/MspI x 100, where HpaII and MspI are the average percentage tail DNA of HpaII- and MspI-digested nucleoids, respectively. To investigate the distribution properties of the percentage $\mathrm{CpG}$ methylation, the bootstrap analytical technique can be employed. The bootstrap is a technique that can estimate population parameters and distribution properties of statistics by substituting the population mechanism used to obtain the parameter with an empirical equivalent. These estimates can be obtained analytically, but they are obtained mostly through the use of resembling and Monte Carlo methods carried out by a computer (Wentzel, et al., 2010).

\subsubsection{Validation of methylation sensitive comet assay results}

To validate the results obtained with the comet assay, we performed the Cytosine Extension Assay (CEA) on the DNA isolated from the remaining cells of the same batch used for the comet assay. The CEA is also based on the selective use of the methylation-sensitive restriction enzymes HpaII and MspI, both of which leave a 5' guanine overhang after DNA cleavage followed by a single nucleotide extension with [3H] dCTP (Pogribny et al, 2004). The level of radioactive cytosine incorporation is then determined by scintillation counting, and the methylation percentage can subsequently be calculated.

The methylation-sensitive comet assay was applied to cultured cells that were treated with the metabolite succinylacetone (SA), which accumulates in hereditary tyrosinemia type I.

Tyrosinemia is a genetic disorder characterized by elevated blood levels of the amino acid tyrosine. Type I tyrosinemia (HT1), the most severe form of tyrosinemia, is caused by a 
defect of the enzyme fumarylacetoacetate hydrolase. Symptoms usually appear in the first few months of life and may include failure to thrive, diarhea, vomiting, jaundice and increased tendency to bleed. Type I tyrosinemia can lead to liver and kidney failure, problems affecting the nervous system, and an increased risk of liver cancer (Al-Dhalimy, 2002; Orejuela, 2008). In a healthy liver, an enzyme mediated five-step process breaks down tyrosine into harmless molecules that are either excreted by the kidneys or used in energy the metabolism. Mutations in the fah gene cause a shortage of the enzyme Fumarylacetoacetate Hydrolase in this multistep pathway. This resulting enzyme deficiency leads to a toxic accumulation of tyrosine and its by-products, which can damage the liver, kidneys, nervous system and other organs and tissues. The exact cause of hepatocellular carcinoma associated with HT1 is unclear at the moment but it is speculated that some of the accumulating metabolites may have carcinogenic properties.

\subsection{Application of the methylation sensitive comet assay}

The HT1 metabolic defect leads to a toxic accumulation of tyrosine and its by-products, which can damage the liver, kidneys, nervous system, and other organs and tissues. The exact cause of hepatocellular carcinoma associated with HT1 is unclear at the moment but because there is some evidence indicating that HTI-accumulating metabolites may alter DNA methylation (Fazzari and Greally, 2004). There is some evidence suggesting that one of the accumulating metabolites of HT1, p-hydroxyphenylpyruvic acid or pHPPA, is responsible for the long-term impairment of the DNA repair, leading ultimately to cellular hepatocarcinoma (van Dyk and Pretorius, 2005).

We examined the effect of another accumulating metabolite of HT1, succinylacetone (SA), on cultured liver cells using the metyhelation sensitive comet assay. The cultured cells were exposed to $50 \mathrm{uM} \mathrm{SA}$ for a period of $24 \mathrm{~h}$, and the comet assay was performed. It was found that in contrast to a notable decline in DNA methylation outside the CpG islands of approximately $20 \%$ after $24 \mathrm{~h}$ of exposure to SA, an increase of approximately $8 \%$ in CpG island methylation was detected after SA treatment (see figure 6). These methylation patterns are typical of those observed in cancer cells (global demethylation and gene specific hypermethylation) and indicates that SA may indeed cause aberrant DNA methylation patterns in HTI, which can contribute to the initiation of hepatocarcinoma associated with this disease (Wentzel, et al., 2010).

It is still not clear if the cell's exposure to SA directly alters the DNA methylation profile, subsequently leading to cancer or if the change in DNA methylation is only a result of important disrupted cellular processes such as DNA repair mechanisms and tumour suppression - caused by the malignant state of the cell.

\section{Summary and conclusion}

Despite the progress that has been made to better our understanding of DNA methylation, it seems we are only at the first chapter of this intricate book and many unanswered questions remain surrounding the extent in which DNA methylation influences normal as well as malignant cell activity. One thing that can be said with certainty is that the main methylation function involves the regulation of gene expression. This function is extended via other actions, e.g. chromatin compaction, $x$-chromosome inactivation, maintaining 


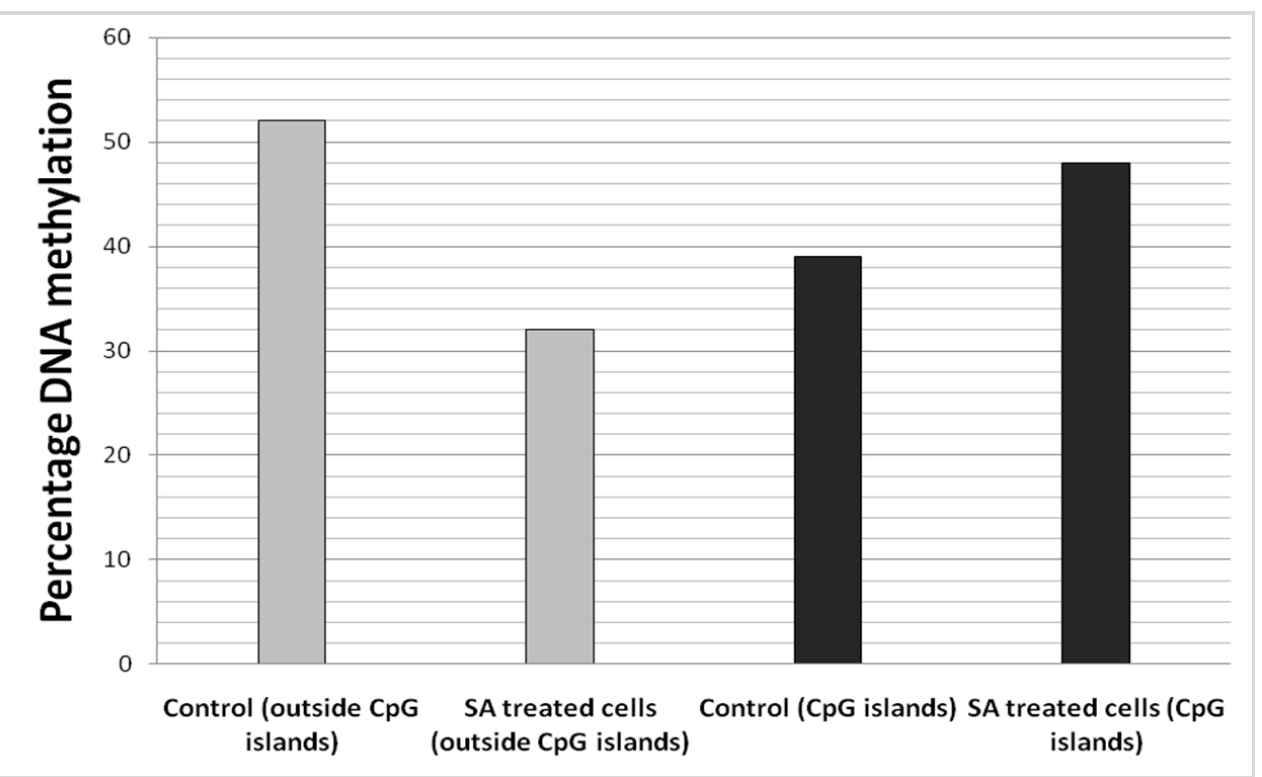

Fig. 6. DNA methylation of HepG2 cells treated with SA. Nucleoids digested with MspI and HpaII give an indication of DNA methylation outside the CpG islands, whereas NotI is used to determine DNA methylation in CpG islands.

genome stability and maintaining cellular identity. These functions are, to a great extent, dependent on the physical properties of cytosine methylation and properly established and maintained DNA methylation patterns seems to be essential for mammalian development and normal functioning of the adult organism.

According to the American Cancer Association nearly 13\% of all deaths worldwide are cancer related. Currently, there are numerous publications suggesting that aberrant DNA methylation patterns play a direct, and likely causative, role in cancer initiation and development. Through better understanding of the role DNA methylation plays in cancer, we can develop more effective treatments for this devastating disease.

The comet assay (single cell gel electrophoresis or SCGE) is a cost-effective, sensitive and simple technique which is traditionally used for analyzing and quantifying DNA damage in individual cells. A variety of DNA lesions can also be detected using the alkaline version of comet assay, including DNA double and single strand breaks (SSB), as well as alkali-labile sites. Modifications to the comet assay have allowed the use of lesion specific endonucleases to detect specific base modifications as DNA single strand breaks.

Experiments with the methylation sensitive comet assay have shown that this technique can be successfully modified to determine changes in the level of global and regional DNA methylation of single cells. The study revealed that the hereditary tyrosinemia type I metabolite succinylacetone, may indeed cause DNA hypermethylation in HTI, which may contribute to the initiation of hepatocarcinoma associated with this disease. 
Metabolic diseases can dramatically alter the metabolism of a cancer cell which can lead to dysfunctional electron transport chain, higher levels of reactive oxygen species and abnormal redox status. It is still unclear if metabolic alterations leads to epigenetic changes or vice versa, but it is apparent that the combination of these two modified states contribute to aberrant gene expression and cancer.

The advantage of the comet assay above other methylation detection techniques is its cost effectiveness, ability to investigate the DNA integrity and the DNA methylation status of cells simultaneously, while being able to measure global as well as gene specific DNA methylation. This modification of the comet assay further expands the versatility of the comet assay by increasing the variety of observations that can be made in one experiment.

One of the drawbacks of this technique is that the assay is very sensitive to external conditions and must be optimized to suite the specific laboratory setting.

Because DNA methylation was shown to be a tissue-specific event (Pogribny, et al., 2004), this modification of the comet assay provides the opportunity to study the DNA methylation status of single cells that are prepared from different tissues under various physiological conditions. By applying the methylation sensitive comet assay to other cancer cell types the technology can be extended to investigate DNA methylation patterns in a variety of cancers.

\section{References}

Andersson, M. A. and B.E.Hellman. (2005). Different roles of Fpg and Endo 111 on catecholinduced DNA damage in extended-term cultures of human lymphocytes and L5178Y mouse lymphoma cells. Toxicology in Vitro. Vol.19, pp. 151-158

Azqueta, A., K. B. Gutzkow, G. Brunborg and A. R. Collins. (2011). Towards a more reliable comet assay: optimising agarose concentration, unwinding time and electrophoresis conditions. Mutation Research. Vol.724, No.1-2, (2011 May), pp. 41-45

Bird, A. (2002). DNA methylation patterns and epigenetic memory. Genes and Development. Vol.16, No.1, (January 2002), pp. 6-21, ISSN 0890-9369

Brenner, C., R. Deplus, C. Didelot, A. Loriot, E. Vire, C. De Smet, A. Gutierrez, D. Danovi, D.

Bernard, T. Boon, P. G. Pelicci, B. Amati, T. Kouzarides, Y. de Launoit, L. Di Croce and F. Fuks. (2005). Myc represses transcription through recruitment of DNA methyltransferase corepressor. Embo Journal. Vol.24, No.2, (December 2004), pp. 336-346

Chakrabarti, R. and C. E. Schutt. (2001). The enhancement of PCR amplification by low molecular-weight sulfones. Gene. Vol.274, No.1-2, pp. 293-298.,

Collins, A., M. Dusinska, M. Franklin, M. Somorovska, H. Petrovska, S. Duthie, L. Fillion, M. Panayiotidis, K. Raslova and N. Vaughan. (1997). Comet assay in human biomonitoring studies: reliability, validation, and applications. Environmental and Molecular Mutagenesis. Vol.30, No.2, pp. 139-146.

Collins, A. R. and I. Gaivao. (2007). DNA base excision repair as a biomarker in molecular epidemiology studies. Molecular Aspects in Medicine. Vol.28, No.3-4, (June 2002), pp. 307-322

Cottrell, S. E. (2004). Molecular diagnostic applications of DNA methylation technology. Clinical Biochemistry. Vol.37, No.7, pp. 595-604., 
Das, P. M. and R. Singal. (2004). DNA methylation and cancer. Journal of Clinical Oncology. Vol.22, No.22, pp. 4632-4642

Duffy, M. J., R. Napieralski, J. W. Martens, P. N. Span, F. Spyratos, F. C. Sweep, N. Brunner, J. A. Foekens and M. Schmitt. (2009). Methylated genes as new cancer biomarkers. European Journal of Cancer. Vol.45, No.3, (January 2009), pp. 335-346

Ehrlich, M. (2002). DNA methylation in cancer: too much, but also too little. Oncogene. Vol.21, No.35, pp. 5400-5413

Epe, B., M. Pflaum, M. Haring, J. Hegler and H. Rudiger. (1993). Use of repair endonucleases to characterize DNA damage induced by reactive oxygen species in cellular and cell-free systems. Toxicology Letters. Vol.67, No.1-3, pp. 57-72

Fairbairn, D. W., P. L. Olive and K. L. O'Neill. (1995). The comet assay: a comprehensive review. Mutation Research. Vol.339, No.1, pp. 37-59

Fazzari, M. J. and J. M. Greally. (2004). Epigenomics: beyond CpG islands. Nature Reviews Genetics.Vol.5, No.6, pp. 446-455

Fujiwara, H. and M. Ito. (2002). Nonisotopic cytosine extension assay: a highly sensitive method to evaluate $\mathrm{CpG}$ island methylation in the whole genome. Anallytical Biochemistry. Vol.307, No.2, pp. 386-389

Gardiner-Garden, M. and M. Frommer. (1987). CpG islands in vertebrate genomes. Journal of Molecular Biology. Vol.196, No.2, pp. 261-282

Gopalakrishnan, S., B. O. Van Emburgh and K. D. Robertson. (2008). DNA methylation in development and human disease. Mutation Research. Vol.647, No.1-2, (Augustus 2008), pp. $30-38$

Guil, S. and M. Esteller. (2009). DNA methylomes, histone codes and miRNAs: tying it all together. International Journal of Biochemistry \& Cell Biol. Vol.41, No.1, (September 2008), pp. 87-95

Haines, T. R., D. I. Rodenhiser and P. J. Ainsworth. (2001). Allele-specific non-CpG methylation of the Nf1 gene during early mouse development. Developmental Biology. Vol.240, No.2, pp. 585-598

Hirst, M. and M. A. Marra. (2009). Epigenetics and human disease. International Journal of Biochemistry \& Cell Biol.Vol.41, No.1, (September 2008) pp. 136-146

Kanai, Y., S. Ushijima, Y. Nakanishi, M. Sakamoto and S. Hirohashi. (2003). Mutation of the DNA methyltransferase (DNMT) 1 gene in human colorectal cancers. Cancer Letters. Vol.192, No.1, pp. 75-82

Klose, R. J. and A. P. Bird. (2006). Genomic DNA methylation: the mark and its mediators. Trends Biochemical Scinces. Vol.31, No.2, (January 2006), pp. 89-97

Lambert, M. P. and Z. Herceg. (2008). Epigenetics and cancer, 2nd IARC meeting, Lyon, France, 6 and 7 December 2007. Mol Oncology. Vol.2, No.1, (March 2008), pp. 33-40

Lovell, D. P. and T. Omori. (2008). Statistical issues in the use of the comet assay. Mutagenesis. Vol.23, No.3, (April 2008), pp. 171-182

Lujambio, A. and M. Esteller. (2007). CpG island hypermethylation of tumor suppressor microRNAs in human cancer. Cell Cycle. Vol.6, No.12, (May 2007), pp. 1455-1459

Mohn, F. and D. Schubeler. (2009). Genetics and epigenetics: stability and plasticity during cellular differentiation. Trends in Genetics. Vol.25, No.3, (January 2009), pp. 129-136

Moss, T. J. and L. L. Wallrath. (2007). Connections between epigenetic gene silencing and human disease. Mutation Research. Vol.618, No.1-2, pp. 163-174 
Nag, R. and M. J. Smerdon. (2009). Altering the chromatin landscape for nucleotide excision repair. Mutation Research. Vol.682, No.1, (January 2009), pp. 13-20

Ohgane, J., S. Yagi and K. Shiota. (2008). Epigenetics: the DNA methylation profile of tissuedependent and differentially methylated regions in cells. Placenta. Vol.29, No.Suppl A, (November 2007), pp. 29-35

Okano, M., D. W. Bell, D. A. Haber and E. Li. (1999). DNA methyltransferases Dnmt3a and Dnmt $3 \mathrm{~b}$ are essential for de novo methylation and mammalian development. Cell. Vol.99, No.3, pp. 247-257

Pogribny, I. P., S. J. James, S. Jernigan and M. Pogribna. (2004). Genomic hypomethylation is specific for preneoplastic liver in folate/methyl deficient rats and does not occur in non-target tissues. Mutation Research. Vol.548, No.1-2, pp. 53-59

Prokhortchouk, E. and P. A. Defossez. (2008). The cell biology of DNA methylation in mammals. Biochimica Biophysica Acta. Vol.1783, No.11, (July 2008), pp. 2167-2173

QIAGEN. 2005. Introducing QIAGEN Proteinase K- the robust proteinase. 04.11.2009 Available from https://www.roche-applied-science.com/pack-insert/3115887a.pdf

Rojas, E., M. C. Lopez and M. Valverde. (1999). Single cell gel electrophoresis assay: methodology and applications. Chromatography B: Biomedical Sciences. Vol.722, No.12, pp. 225-254

Sawan, C., T. Vaissiere, R. Murr and Z. Herceg. (2008). Epigenetic drivers and genetic passengers on the road to cancer. Mutation Research. Vol.642, No.1-2, (March 2008), pp. 1-13

Speit, G., M. Vasquez and A. Hartmann. (2009). The comet assay as an indicator test for germ cell genotoxicity. Mutation Research. Vol.681, No.1, (March 2008), pp. 3-12

Sweatt, J. D. (2009). Experience-dependent epigenetic modifications in the central nervous system. Biological Psychiatry. Vol.65, No.3, (November 2008), pp. 191-197

Szyf, M. (2006). Targeting DNA methylation in cancer. Bull Cancer. Vol.93, No.9, pp. 961-972

Tice, R. R., E. Agurell, D. Anderson, B. Burlinson, A. Hartmann, H. Kobayashi, Y. Miyamae,

E. Rojas, J. C. Ryu and Y. F. Sasaki. (2000). Single cell gel/comet assay: guidelines for in vitro and in vivo genetic toxicology testing. Environmental and Molecular Mutagenesis. Vol.35, No.3, pp. 206-221

Tost, J. (2009). DNA methylation: an introduction to the biology and the disease-associated changes of a promising biomarker. Methods in Molecular Biology. Vol.507, pp3-20

Tsou, J. A., J. A. Hagen, C. L. Carpenter and I. A. Laird-Offringa. (2002). DNA methylation analysis: a powerful new tool for lung cancer diagnosis. Oncogene. Vol.21, No.35, pp. 5450-5461

van Dyk, E. and P. J. Pretorius. (2005). DNA damage and repair in mammalian cells exposed to p-hydroxyphenylpyruvic acid. Biochemical and Biophysical Research Communications. Vol.338, No.2, (October 2005), pp. 815-819

Waggoner, D. (2007). Mechanisms of Disease: Epigenesis. Seminars in Pediatric Neurology. Vol.14, No.1, pp. 7-14

Wentzel, J. F., C. Gouws, C. Huysamen, E. Dyk, G. Koekemoer and P. J. Pretorius. (2010). Assessing the DNA methylation status of single cells with the comet assay. Analytical Biochemistry Vol.400, No.2, (February 2010) , pp. 190-194

Wilson, A. S., B. E. Power and P. L. Molloy. (2007). DNA hypomethylation and human diseases. Biochimica Biophysica Acta. Vol.1775, No.1, (September 2006), pp. 138-162 


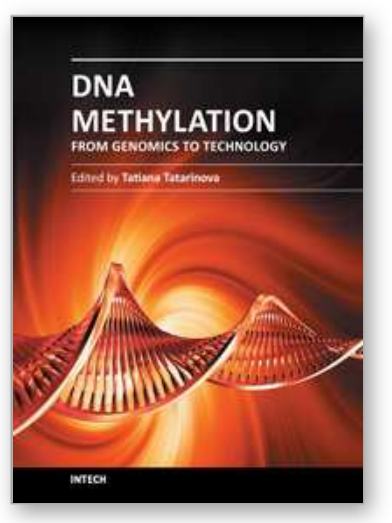

\author{
DNA Methylation - From Genomics to Technology \\ Edited by Dr. Tatiana Tatarinova
}

ISBN 978-953-51-0320-2

Hard cover, 400 pages

Publisher InTech

Published online 16, March, 2012

Published in print edition March, 2012

Epigenetics is one of the most exciting and rapidly developing areas of modern genetics with applications in many disciplines from medicine to agriculture. The most common form of epigenetic modification is DNA methylation, which plays a key role in fundamental developmental processes such as embryogenesis and also in the response of organisms to a wide range of environmental stimuli. Indeed, epigenetics is increasing regarded as one of the major mechanisms used by animals and plants to modulate their genome and its expression to adapt to a wide range of environmental factors. This book brings together a group of experts at the cutting edge of research into DNA methylation and highlights recent advances in methodology and knowledge of underlying mechanisms of this most important of genetic processes. The reader will gain an understanding of the impact, significance and recent advances within the field of epigenetics with a focus on DNA methylation.

\title{
How to reference
}

In order to correctly reference this scholarly work, feel free to copy and paste the following:

Johannes F. Wentzel and Pieter J. Pretorius (2012). Investigating the Role DNA Methylations Plays in Developing Hepatocellular Carcinoma Associated with Tyrosinemia Type 1 Using the Comet Assay, DNA Methylation - From Genomics to Technology, Dr. Tatiana Tatarinova (Ed.), ISBN: 978-953-51-0320-2, InTech, Available from: http://www.intechopen.com/books/dna-methylation-from-genomics-to-technology/investigatingthe-role-dna-methylations-plays-in-developing-hepatocellular-carcinoma-associated-with

\section{INTECH}

open science | open minds

\section{InTech Europe}

University Campus STeP Ri

Slavka Krautzeka 83/A

51000 Rijeka, Croatia

Phone: +385 (51) 770447

Fax: +385 (51) 686166

www.intechopen.com

\section{InTech China}

Unit 405, Office Block, Hotel Equatorial Shanghai

No.65, Yan An Road (West), Shanghai, 200040, China

中国上海市延安西路65号上海国际贵都大饭店办公楼 405 单元

Phone: +86-21-62489820

Fax: $+86-21-62489821$ 
(C) 2012 The Author(s). Licensee IntechOpen. This is an open access article distributed under the terms of the Creative Commons Attribution 3.0 License, which permits unrestricted use, distribution, and reproduction in any medium, provided the original work is properly cited. 